oPEN $\mathrm{MnO}_{2}$ Nanorods Intercalating

SUBJECT AREAS:

ELECTRONIC PROPERTIES

AND DEVICES

ELECTRONIC MATERIALS

Received

17 March 2014

Accepted

4 April 2014

Published

28 April 2014

Correspondence and requests for materials should be addressed to W.H.T. (whtang@mail. njust.edu.cn)

\title{
Graphene Oxide/Polyaniline Ternary Composites for Robust High-Performance Supercapacitors
}

Guangqiang Han', Yun Liu', Lingling Zhang' ', Erjun Kan², Shaopeng Zhang' , Jian Tang' \& Weihua Tang'

\begin{abstract}
'Key Laboratory of Soft Chemistry and Functional Materials (Ministry of Education of China), Nanjing University of Science and Technology, Nanjing 210094, People's Republic of China, ${ }^{2}$ Department of Applied Physics, Nanjing University of Science and Technology, Nanjing 210094, P. R. China.
\end{abstract}

New ternary composites of $\mathrm{MnO}_{2}$ nanorods, polyaniline (PANI) and graphene oxide (GO) have been prepared by a two-step process. The $100 \mathrm{~nm}$-long $\mathrm{MnO}_{2}$ nanorods with a diameter $\sim 20 \mathrm{~nm}$ are conformably coated with PANI layers and fastened between GO layers. The $\mathrm{MnO}_{2}$ nanorods incorporated ternary composites electrode exhibits significantly increased specific capacitance than PANI/GO binary composite in supercapacitors. The ternary composite with $70 \% \mathrm{MnO}_{2}$ exhibits a highest specific capacitance reaching $512 \mathrm{~F} / \mathrm{g}$ and outstanding cycling performance, with $\sim 97 \%$ capacitance retained over 5000 cycles. The ternary composite approach offers an effective solution to enhance the device performance of metal-oxide based supercapacitors for long cycling applications.

upercapacitor or electrochemical capacitors, featuring high power density, long cycle life, fast charge and discharge rates ${ }^{1-7}$, have attracted tremendous attention in energy storage. During the last decades, different kinds of materials have been studied as possible supercapacitor electrodes, namely, carbonaceous materials, conducting polymers and transition metal oxides ${ }^{8-11}$. Among them, transition-metal oxides such as $\mathrm{RuO}_{2}{ }^{12-13}$, $\mathrm{NiO}^{14,15}$ and $\mathrm{MnO}_{2}{ }^{16-20}$, are the most widely used electrode materials thanks to their large capacitance, high surface area and relatively good electrical conductivity. Compared to other transition-metal oxides, $\mathrm{MnO}_{2}$ is generally regarded as the most promising one for the next generation of supercapacitors because of its ideal capacitor performances, good cycle stability, low cost and environmental friendliness ${ }^{21,22}$. However, the poor electrical conductivity and densely packed structure limit its application in the development of high-performance supercapacitors ${ }^{23}$. For this purpose, some efforts have been made to develop nanostructured $\mathrm{MnO}_{2} /$ carbonacenous materials (ca. graphene, carbon nanotube or carbon nanofibers) based binary composites ${ }^{24,25}$ or their ternary composites with conducting polymers ${ }^{26-31}$. The carbonaneous materials or conductive polymers act as not only $3-$ dimensional (3-D) scaffold but conductive wrappings to enhance the specific capacitance and cycle stability of the electrodes fabricated with these composites. Our recent studies have shown that conductive polymer coatings prepared via in-situ redox process can greatly improve the conductivity and specific area of the resulted composites $^{32,33}$.

As one of the most appealing carbon materials, graphene features superior electrical conductivity, excellent mechanical flexibility, and high thermal and chemical stability ${ }^{34,35}$. Compared with pristine graphene, graphene oxide (GO) has good dispersion in many solvents, particularly in water, and this is important for solutionprocessing and further derivatization ${ }^{36,37}$. Though some losses in electrical conductivity when converting from graphite, $\mathrm{GO}$ has demonstrated to be a potential substrate to improve the conductivity and stability of $\mathrm{MnO}_{2}{ }^{38}$. To enhance the performance of $\mathrm{MnO}_{2}$-graphene composite electrodes, conductive materials were further incorporated to form ternary composites composites to achieved significantly increased specific capacitance and cyclingstability from the ternary composites based supercapacitors ${ }^{26-31}$. By depositing 5-10 $\mathrm{nm} \mathrm{MnO}_{2} /$ polyaniline (PANI) nanoparticles onto sulfonated graphene nanosheets, the composite (sGMOPANI) based two-electrode cell showed an electrochemical capacitance of $276 \mathrm{~F} / \mathrm{g}$ at $1 \mathrm{~A} / \mathrm{g}$ current density $\mathrm{y}^{30}$. The ternary composites of graphene $/ \mathrm{MnO}_{2}$ nanostructures with carbon nanotube or poly(3,4-ethylenedioxythiophene):poly(styrenesulfonate) showed $\sim 20 \%$ or $45 \%$ increased capacitance than graphene $/ \mathrm{MnO}_{2}$ composites, with the highest value as 

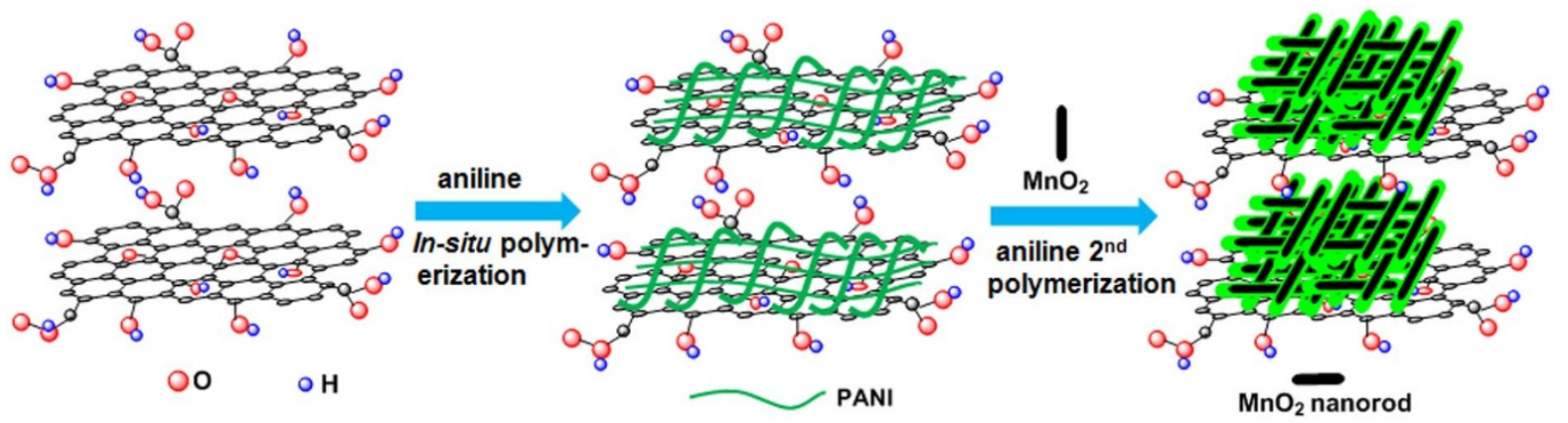

Figure 1 | Illustration for formation of GOPM nanocomposites: (a) in-situ polymerization of aniline, (b) dispersion of graphene oxide sheets and $\mathrm{MnO}_{2}$ nanorods in solution by ultrasonication and self-assembly during the second aniline polymerization.

high as $\sim 380 \mathrm{~F} / \mathrm{g}$ achieved $^{28}$. The nanostructure of graphene $/ \mathrm{MnO}_{2}$ seems to be important for the performance and stability of the capacitors. Moreover, the overall specific capacitance of $\mathrm{MnO}_{2} /$ carbon composites is generally limited to $250 \mathrm{~F} / \mathrm{g}$ due to the relatively low weight loading of $\mathrm{MnO}_{2}$ on carbon surface (usually less than 64 wt.\%) $)^{25}$. We were intrigued whether the high loading of $\mathrm{MnO}_{2}$ nanorods into binary composites of conductive polymers and solution-exfoliated GO nanosheets can improve the electron transport and contribute to the energy storage of the whole composite film to achieve robust high-performance supercapacitors.

We report herein the successful fabrication of graphene oxidepolyaniline- $\mathrm{MnO}_{2}$ ternary composites, where $\mathrm{MnO}_{2}$ nanorods were incorporated to intercalate PANI/solution-exfoliated GO nanosheets. $\mathrm{MnO}_{2}$ nanorods were thus fastened onto $\mathrm{GO}$ sheets via PANI layer (Fig. 1). The PANI layer has several advantages: (1) to anchor $\mathrm{MnO} 2$ nanorods onto the surface of GO, (2) to prevent GO sheets and $\mathrm{MnO}_{2}$ nanorods from stacking/aggregating; (3) to improve the charge transfer between $\mathrm{GO}$ and $\mathrm{MnO}_{2}$ and (4) to prevent $\mathrm{MnO}_{2}$ from falling off GO sheets during cycling electrochemistry. The composites exhibited greatly improved capacitive performance than GO- $\mathrm{MnO}_{2}$ and GO-PANI composites. The ternary composites with 70 wt.\% $\mathrm{MnO}_{2}$ delivered a highest specific capacitance of $512 \mathrm{~F} / \mathrm{g}$ at $0.25 \mathrm{~A} / \mathrm{g}$ current density, with the capacitive retention of as high as $97 \%$ observed after 5100 cycles.

\section{Results}

Preparation and characterization of ternary composites. The ternary composites were prepared with a two-step protocol as shown in Fig. 1. After a first step of coating solution-exfoliated GO nanosheets ${ }^{39}$ with polyaniline, $\mathrm{MnO}_{2}$ nanorods ${ }^{40}$ were allowed to self-assembly onto the GO sheets and then wrapped by in-situ prepared polyaniline coatings in the second step. The $\mathrm{MnO}_{2}$ (in weight ratio) content in the ternary composites was determined with thermogravimetric (TGA) analysis (Figure 2). Hence, the asprepared $\mathrm{MnO}_{2}$-PANI-GO composites (GOPM) are designated as GOPM-20, GOPM-46 and GOPM-70, meaning that mass percentage of $\mathrm{MnO}_{2}$ in the composites is about $20 \%, 46 \%$ and $70 \%$, respectively.

Typical X-ray diffraction (XRD) pattern of as-prepared hierarchical porous GOPM-46 and free $\mathrm{MnO}_{2}, \mathrm{PANI}$ and GO are shown in Fig. 3a. It can be seen that the XRD pattern of GOPM is similar to those of free $\mathrm{MnO}_{2}$ and PANI, indicating that the $\mathrm{MnO}_{2}$ particles have been well immobilized by PANI onto GO substrate. All of the major reflections $\left[2 \theta=21.2^{\circ}(120), 28.0^{\circ}(310), 37.5^{\circ}(131), 42.5^{\circ}\right.$ (300), $59.0^{\circ}(160)$ and $\left.69.7^{\circ}(003)\right]$ in the XRD pattern can be indexed to the orthorhombic phase of $\gamma-\mathrm{MnO}_{2}$ with lattice constants $a=6.36$ $\AA, b=10.15 \AA$ and $c=4.09 \AA$ (JCPDS 14-644), confirming that $\gamma$ $\mathrm{MnO}_{2}$ crystalline phase forms in the synthesis, which is in good agreement with the reported patterns for $\gamma-\mathrm{MnO}_{2}{ }^{41}$. The broad peak centered at about $25.3^{\circ}$, attributing to the diffraction of (110) plane of the as-formed PANI crystalline phase, suggests the successful synthesis of PANI. However, the sharp peak at $2 \theta=11.0^{\circ}$, corresponding to its (002) plane for pure $\mathrm{GO}^{42}$, almost disappeared, which is attributed to the increase in inter-space distance of graphene layer due to intercalation of $\mathrm{PANI} / \mathrm{MnO} 2$ between $\mathrm{GO}$ sheets.

The Raman spectra of GOPM and pristine components are shown in Fig. 3b. It can be clearly seen that both GOPM-46 and $\mathrm{MnO}_{2}$ samples feature a sharp peak at $640 \mathrm{~cm}^{-1}$, corresponding to the $\mathrm{Mn}-\mathrm{O}$ vibration perpendicular to the direction of the $\mathrm{MnO}_{6}$ octahedral double chains of $\mathrm{MnO}_{2}{ }^{43}$. The Raman-active peaks at $1350 \mathrm{~cm}^{-1}$ and $1600 \mathrm{~cm}^{-1}$, corresponding to the in-plane bondstretching motion of $\mathrm{C} \mathrm{sp^{2 }}$ atoms ( $\mathrm{G}$ band) and the breathing modes of or of benzenoid rings of GO (D-band), were significantly suppressed in intensity for GOPM-46 sample. The typical peaks for PANI also weakened in GOPM, mainly due to its low content in the hybrid composite.

To confirm the XRD and Raman results, the compositions and the valence states of GOPM were further characterized with XPS and the results are shown in Fig. 3c-f. The peak $\sim 284.6 \mathrm{eV}$ (for C 1s) originating from the graphitic $\mathrm{sp}^{2}$ carbon atoms and the peak at $531.9 \mathrm{eV}$ corresponding to $\mathrm{O} 1 \mathrm{~s}$ in $\mathrm{C}-\mathrm{OH}$ bond are observed for GO (Fig. 3c). The existence of C, N, O, Mn in GOPM can be confirmed from Fig. 3d. For GOMP, the XPS peaks of N 1s (Fig. 3e) are further decomposed into three Gaussian peaks with binding energies of $398.6(-\mathrm{N}=), 399.7(-\mathrm{NH}-)$ and $400.1\left(-\mathrm{N}^{+}\right)^{37}$. The peak at $400.1 \mathrm{eV}$ is assigned to the quinoid amine and nitrogen cationic radical $\left(\mathrm{N}^{+}\right)$, while the one at $398.6 \mathrm{eV}(=\mathrm{N}-)$ is due to benzenoid amine. The Mn $2 p$ spectrum is analyzed in Fig. 3f. Both Mn 2p $\mathrm{p}_{3 / 2}$ peak at $643.0 \mathrm{eV}$ and $\mathrm{Mn} 2 \mathrm{p}_{1 / 2}$ peak centering at $654.5 \mathrm{eV}$ are clearly observed, which are in good agreement with the energy splitting of the standard spectrum of $\mathrm{MnO}_{2}{ }^{44}$. The peak-to-peak separation between $\mathrm{Mn} 2 \mathrm{p}_{1 / 2}$ and $\mathrm{Mn} 2 \mathrm{p}_{3 / 2}$ level is $11.5 \mathrm{eV}$, which is approximately the same value as that literature for $\mathrm{MnO}_{2}{ }^{45}$.

The morphologies of dry $\mathrm{MnO}_{2}$, GO-PANI and GOPM-46 are observed with FESEM and TEM (Fig. 4,5). Pristine $\mathrm{MnO}_{2}$ nanorods

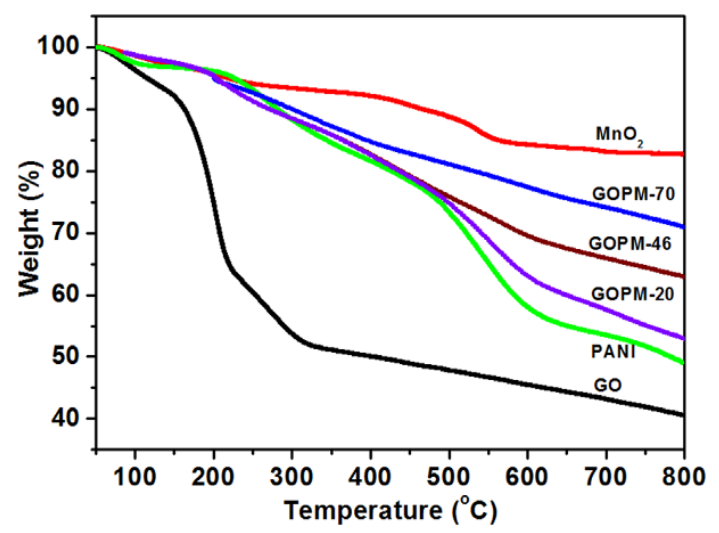

Figure $2 \mid$ TGA curves of GO, PANI, $\mathrm{MnO}_{2}$ and GOPM. 

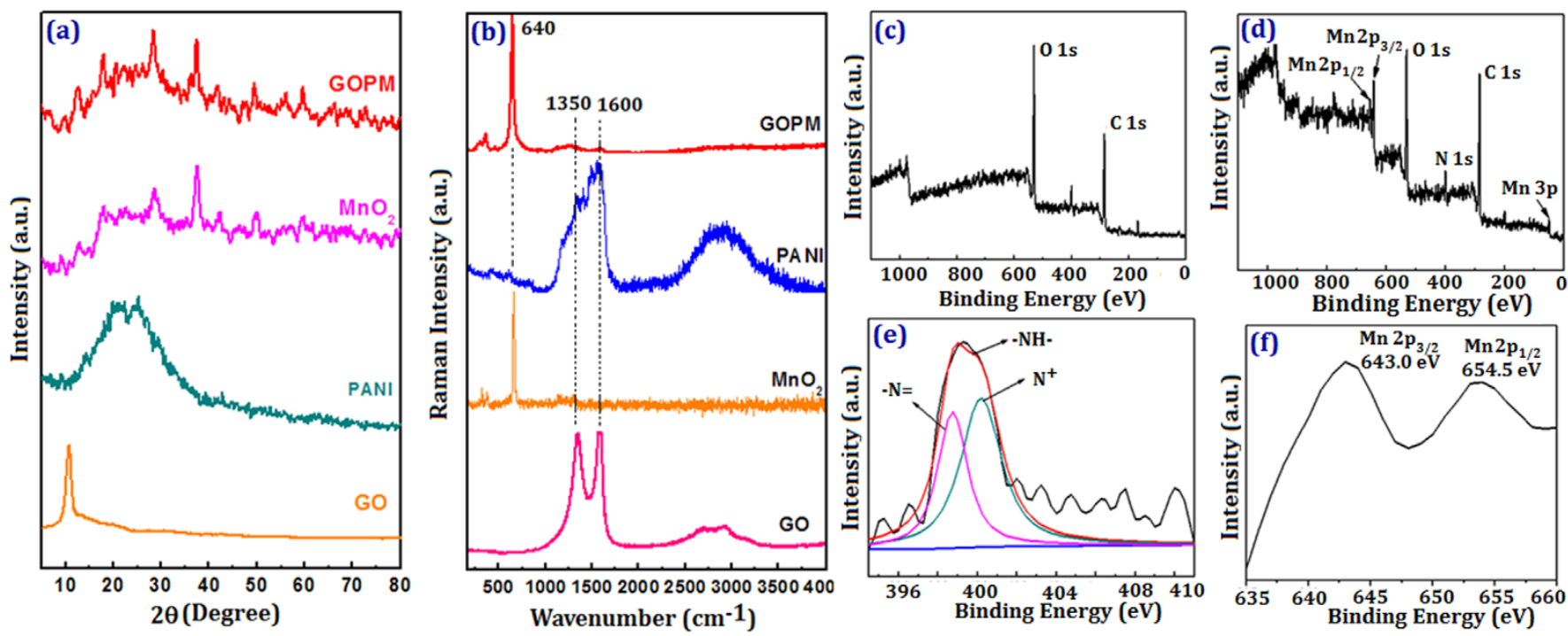

Figure 3 | (a) X-ray diffraction patterns and (b) Raman spectra of GO, $\mathrm{MnO}_{2}$, PANI, GOPM-46; XPS spectra of (c) GO, (d) GOPM-46 and N 1s in (e) GOPM-46 and (f) Mn 2p in GOPM-46.

with a length of $200 \mathrm{~nm}$ grow into nanospheres with diameters ranging from 300 to $600 \mathrm{~nm}$ (Fig. 4a). The in-situ prepared PANI selfassembled on GO sheets like a broccoli composed numerous of small flower buds with a diameter of $50 \mathrm{~nm}$ (Fig. 4b). When $\mathrm{MnO}_{2}$ nanorods were introduced to GO-PANI system, GOPM hybrid composites feature a porous yet densely packed structure (Fig. 4c), with GO layers intercalated by porous interpenetrating networks of PANIwrapped $\mathrm{MnO}_{2}$ nanorods. PANI functions as both protecting coating for $\mathrm{MnO}_{2}$ nanorods to avoid aggregation and adhesive to fasten GO sheets and $\mathrm{MnO}_{2}$ nanorods into densely packed structure. Exfoliated GO sheets feature transparent wrinkled tulle in TEM image (Fig. 4d), while PANI formed a compact layer on top of GO sheets for GO-PANI composites.

A close look at the TEM images of GOPM (Fig. $4 \mathrm{f}$ and Fig. 5c,d), one would clearly observed the existence of $\mathrm{MnO}_{2}$ nanorods, featuring a length less than $100 \mathrm{~nm}$ and a diameter $\sim 20 \mathrm{~nm}$. With the content of $\mathrm{MnO}_{2}$ nanorods increasing from $46 \%$ to $70 \%$ in the composites, the dimensions of $\mathrm{MnO}_{2}$ nanorods was observed to increase by $30 \%$ (Fig. $5 \mathrm{~d}$ ). Nevertheless, the intimate contact between GO sheets and PANI wrapped $\mathrm{MnO}_{2}$ nanorods with different lengths can be clearly observed from both SEM and TEM images, which is important for improving electrical conductivity. A close look at the SEM image of ternary composites, GOPM-70 boasts increased porosity than GOPM-46, which can be confirmed by BET measurement. The GOPM-70 and GOPM-46 exhibit a surface area of 91.37 and $73.65 \mathrm{~m}^{2} / \mathrm{g}$, respectively, much higher than that for GO-PANI $\left(\sim 36.92 \mathrm{~m}^{2} / \mathrm{g}\right)$. The increased surface area can be explained with the constitution of the ternary composites. Since PANI has the equivalent mass with $\mathrm{GO}$, more $\mathrm{MnO}_{2}$ nanorods were uncovered by PANI with the increase of $\mathrm{MnO}_{2}$ content. More porous structure was therefore obtained to present higher surface area before heavy aggregation of $\mathrm{MnO}_{2}$ occurs.

Capacitive performance of ternary composite. The capacitive performance of $\mathrm{GO}, \mathrm{MnO}_{2}, \mathrm{GO}-\mathrm{PANI}, \mathrm{GO}-\mathrm{MnO}_{2}$ and GOPM were evaluated by cycle voltammetry $(\mathrm{CV})$ and galvanostatic
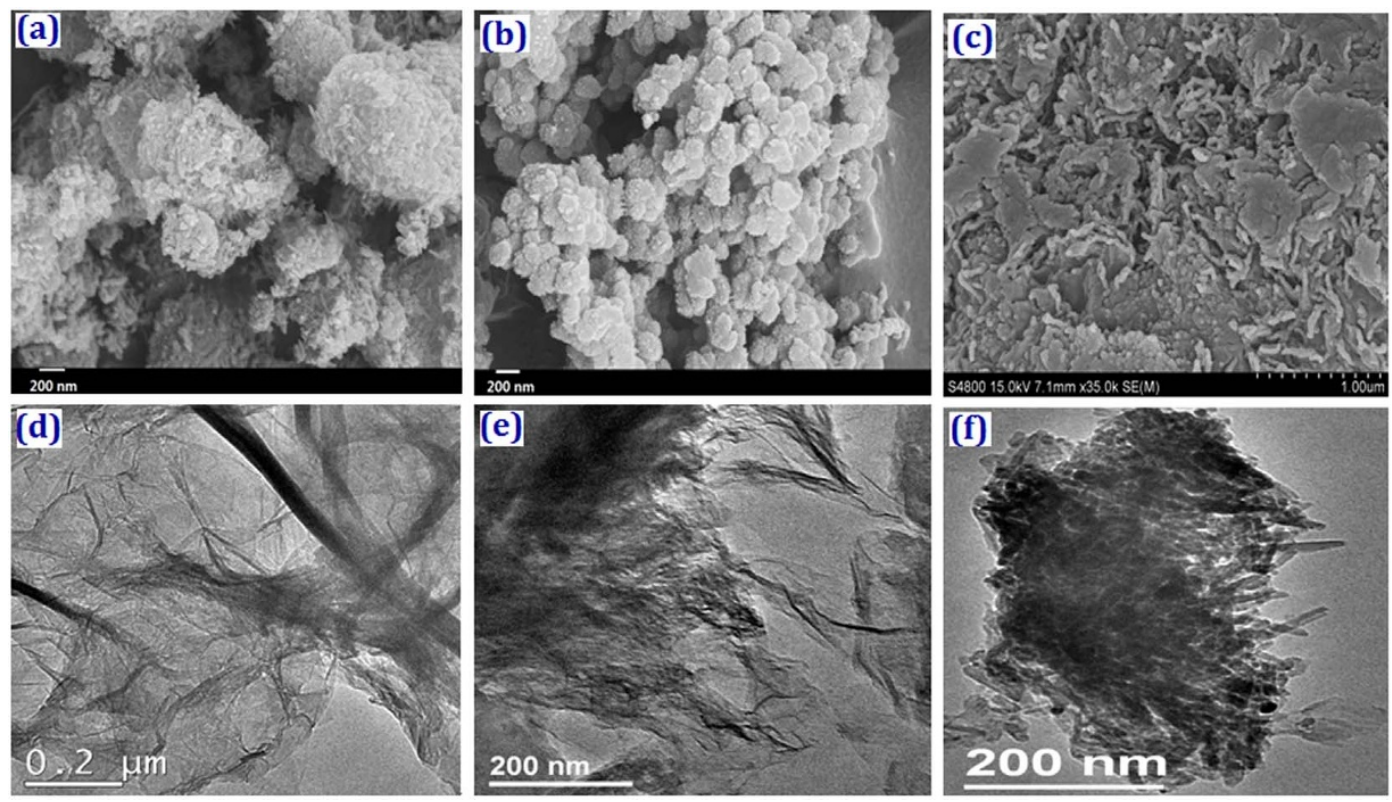

Figure 4 FE-SEM images of (a) dried pristine $\mathrm{MnO}_{2}$, (b) GO-PANI and (c) GOPM-46; TEM images of (d) GO sheets, (e) GO-PANI and (f) GOPM-46. 

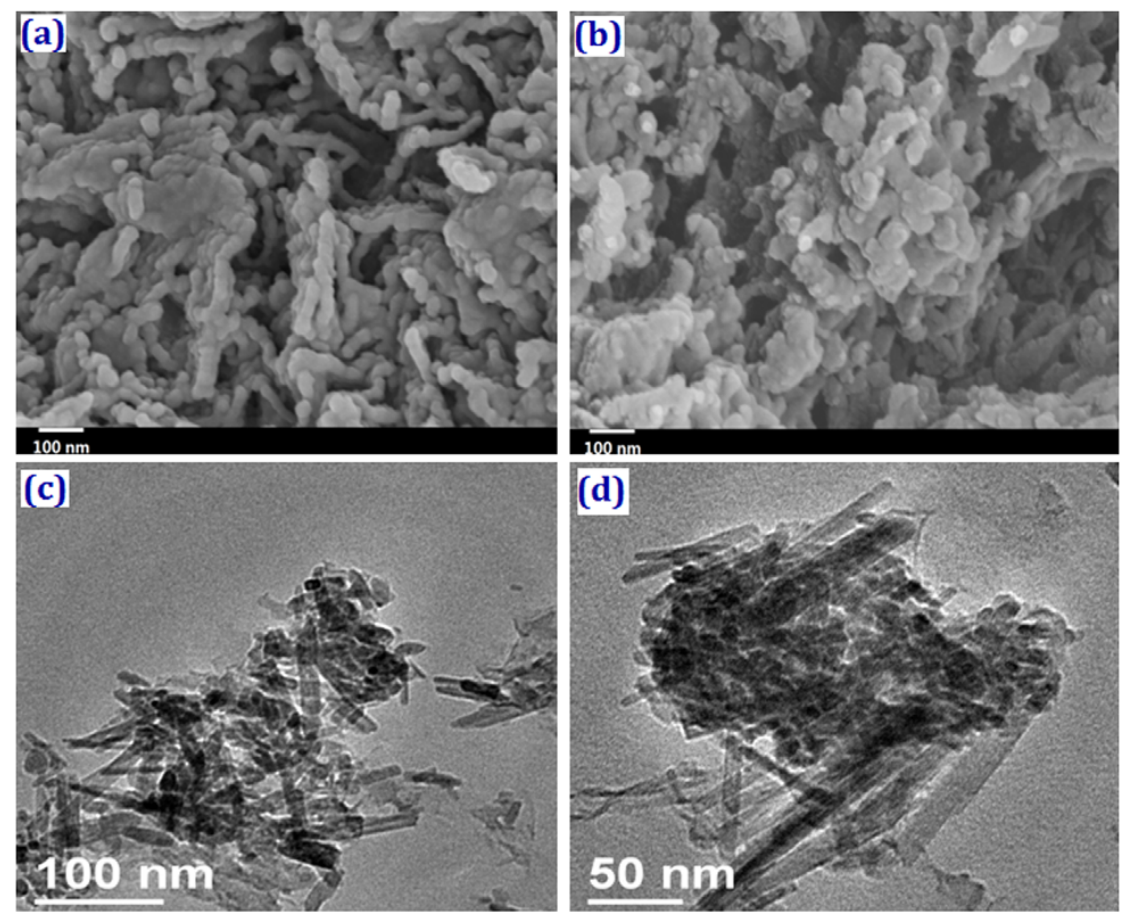

Figure 5 FE-SEM image of (a) GOPM-46 and (b) GOPM-70, TEM image of (c) GOPM-46 and (d) GOPM-70.

charge/discharge techniques in $1 \mathrm{M} \mathrm{Na}_{2} \mathrm{SO}_{4}$ solutions. Fig. 6a shows the $\mathrm{CV}$ curves of GOPM-46 at different scan rates. At low scan rates ( $\leq 50 \mathrm{mV} / \mathrm{s}$ ), GOPM-46 exhibits slight redox peaks, suggesting the pseudocapacitance feature of GOPM. The asymmetrical CV curves can be attributed to the combined double-layer and pseudocapacitive contributions to the total capacitance. The high CV currents indicate the high conductivity and low internal resistance for GOPM as the electrode material. Fig. $6 \mathrm{~b}$ shows $\mathrm{CV}$ curves of $\mathrm{GO}, \mathrm{MnO}_{2}, \mathrm{GO}-$ PANI, GO- $\mathrm{MnO}_{2}$ and GOPM at $50 \mathrm{mV} \mathrm{s}{ }^{-1}$, where GOPM-46 exhibits the highest capacitance than other electrodes. This can be attributed to the unique porous structure of hybrid GOPM, which effectively prevent the self-aggregation of GO sheets and $\mathrm{MnO}_{2}$ nanorods. More importantly, the hybrid GOPM with PANI-coated $\mathrm{MnO}_{2}$ nanorods intercalated GO nanosheets affords higher surface area to provide better conductive paths for fast electron transportation.

The galvanostatic charge/discharge curves of GOPM in $1 \mathrm{M}$ $\mathrm{Na}_{2} \mathrm{SO}_{4}$ solution were carried out at a current density of $0.25,0.5$,
1, 2 and $4 \mathrm{~A} / \mathrm{g}$. As illustrated in Fig. 7a, all the curves exhibit an equilateral triangle shape, indicating high reversibility of the hybrid materials during charge/discharge process. The charging/discharging process took longer time at lower current density, which is attributed to the sufficient insertion or release of $\mathrm{Na}^{+}$during the charging/discharging process. The specific capacitance $(C)$ of the electrode can be calculated according to equation: $\mathrm{C}=\mathrm{It} / \mathrm{mV}$, where $\mathrm{C}$ is the specific capacitance $(\mathrm{F} / \mathrm{g})$, I is the charge-discharge current (A), $t$ is the discharge time (s), $\mathrm{V}$ is the potential window $(\mathrm{V}), \mathrm{m}$ is the mass of active material in the working electrode $(\mathrm{g})^{46}$. The galvanostatic charge/discharge curves of $\mathrm{MnO}_{2}, \mathrm{GO}-\mathrm{MnO}_{2}, \mathrm{GO}-\mathrm{PANI}$, GOPM at $0.25 \mathrm{~A} / \mathrm{g}$ current density are compared in Fig. $7 \mathrm{~b}$. The specific capacitance of GOPM $(409 \mathrm{~F} / \mathrm{g})$ is much higher than that of $\mathrm{MnO}_{2}(150 \mathrm{~F} / \mathrm{g}), \mathrm{GO}-\mathrm{MnO}_{2}(162 \mathrm{~F} / \mathrm{g})$ and GO-PANI $(20 \mathrm{~F} / \mathrm{g})$ at the same current density. Same trend is observed for GOPM when further increasing current density in the range of $0.25 \sim 4 \mathrm{~A} / \mathrm{g}$ (Fig. 7c), indicating the robustness of the as-prepared hybrid GOPM as electrode materials.
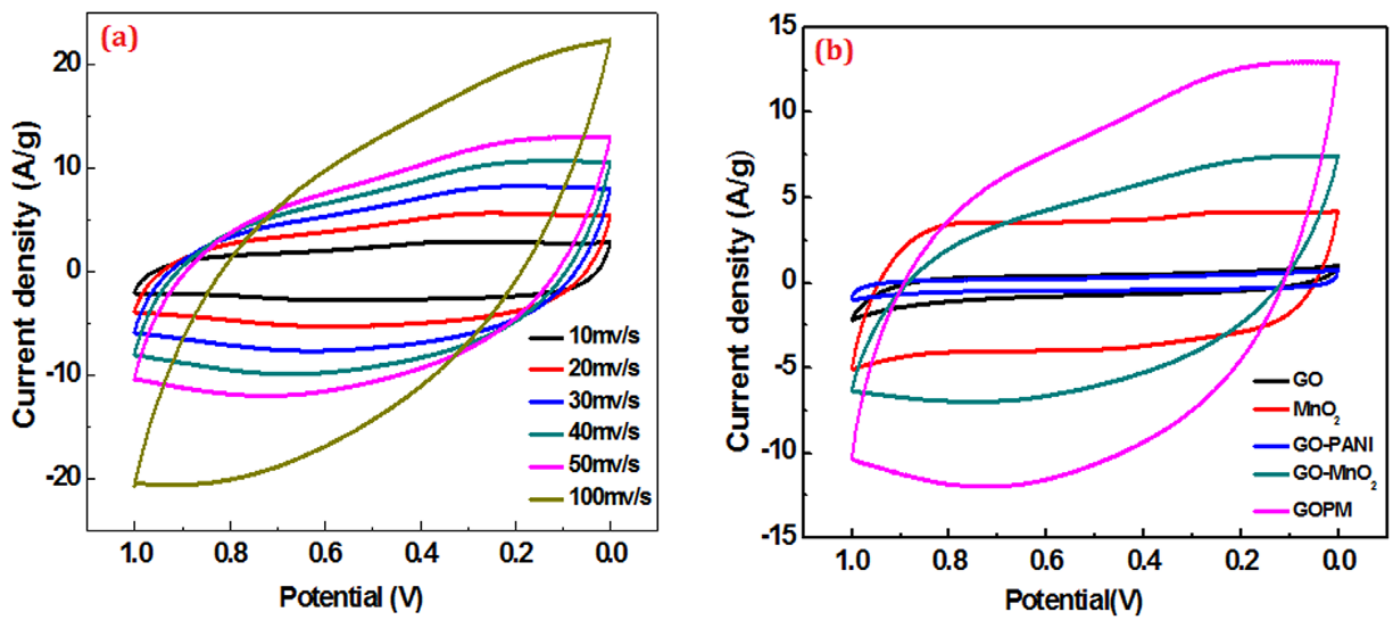

Figure 6 | (a) CV curves of GOPM-46 at scan rate of 10, 20, 30, 40, 50 and $100 \mathrm{mVs}^{-1}$; (b) CV curves of GO, MnO, GO-PANI, GO-MnO 2 and GOPM-46 at scan rate of $50 \mathrm{mV} \mathrm{s}^{-1}$. 

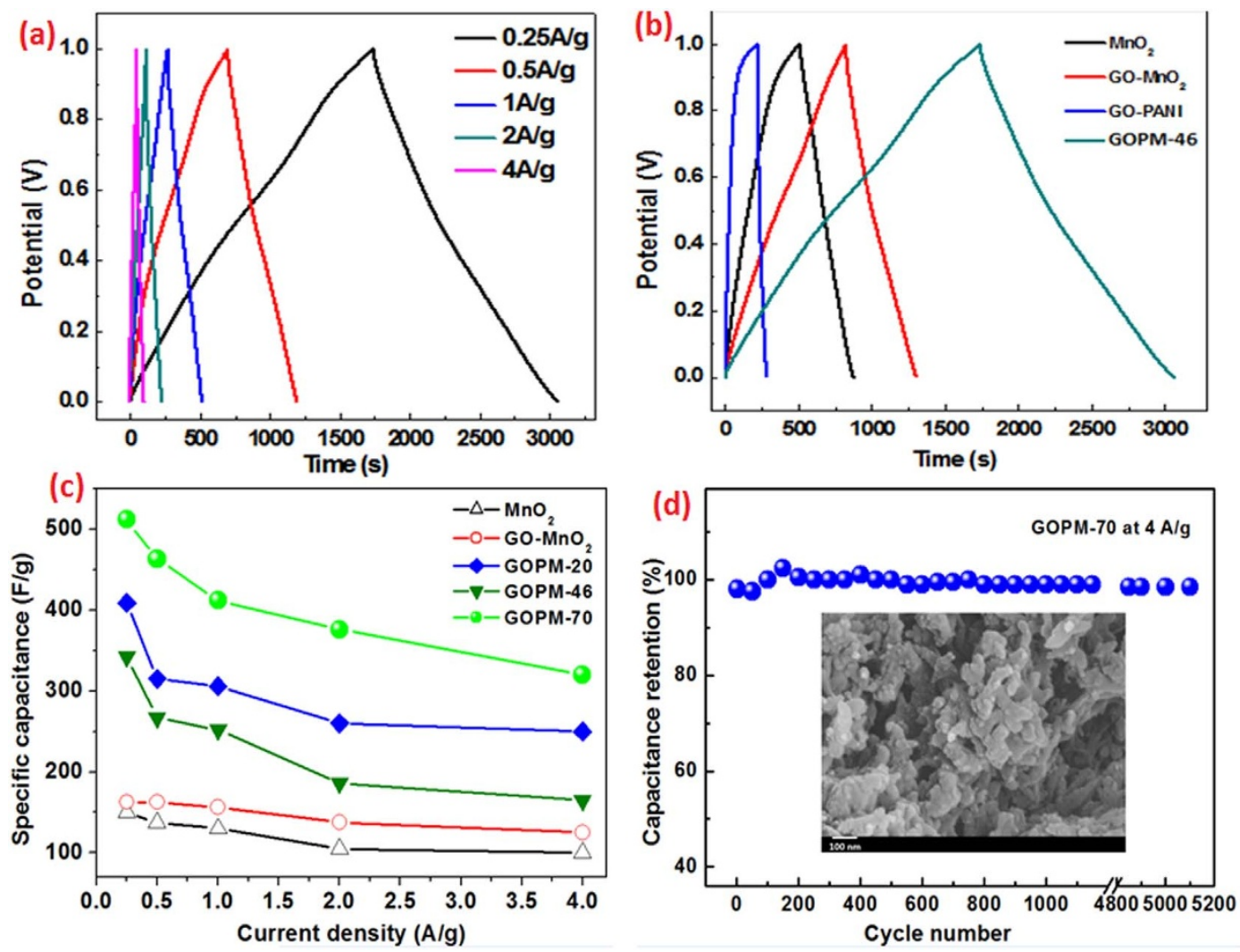

Figure 7 | Galvanostatic charge/discharge curves of (a) GOPM-46 at different current density; (b) $\mathrm{MnO}_{2}, \mathrm{GO}-\mathrm{MnO}_{2}$, GO-PANI and GOPM-46 at $0.25 \mathrm{~A} / \mathrm{g}$ current density; (c) specific capacitance curves of $\mathrm{MnO}_{2}, \mathrm{GO}-\mathrm{MnO}_{2}$ and $\mathrm{GOPM}$ composites at different current densities; (d) capacitance retention of GOPM-70 over cycling times.

The specific capacitance of GOPM is found to increase with the content of $\mathrm{MnO}_{2}$ in the composite, as shown in Fig. 7c. The specific capacitance of GOPM-70 (412 F/g), GOPM-46 (306 F/g) and GOPM-20 $(252 \mathrm{~F} / \mathrm{g})$ is about $1 \sim 2$ times higher than that of $\mathrm{MnO}_{2}$ $(130 \mathrm{~F} / \mathrm{g})$ and $\mathrm{GO}-\mathrm{MnO}_{2}(156 \mathrm{~F} / \mathrm{g})$ at the current density of $1 \mathrm{~A} / \mathrm{g}$. Further increase of $\mathrm{MnO}_{2}$ content over $90 \%$, however, leads to decreased capacitive performance, e.g., the GOPM with $92 \% \mathrm{MnO}_{2}$ delivered a specific capacitance of $382 \mathrm{~F} / \mathrm{g}$ at $1 \mathrm{~A} / \mathrm{g}$ current density. The specific capacitance of $412 \mathrm{~F} / \mathrm{g}$ at $1 \mathrm{~A} / \mathrm{g}$ for GOPM-70 is much better than graphene $/ \mathrm{MnO}_{2}\left(78\right.$ wt.\% $\mathrm{MnO}_{2}$ ) binary composite under similar testing conditions ${ }^{25}$. This improvement may be explained with the contribution of conductive PANI in facilitating charge transport and energy storage. Compared with the ternary composite sGMOPANI ${ }^{30}$, our composite with $\mathrm{MnO}_{2}$ nanorods exhibited $11 \%$ improved capacitance in supercapacitors at same current density of $1 \mathrm{~A} / \mathrm{g}$. The specific capacitance of GOPM decreases with current density, with $\sim 62 \%$ capacitance retained for GOPM-70 when the current density increased from $0.25 \mathrm{~A} / \mathrm{g}$ to $4 \mathrm{~A} / \mathrm{g}$.

The electrochemical stability of GOPM-70 nanocomposites was investigated at $4 \mathrm{~A} / \mathrm{g}$ current density. As shown in Fig. 6d, the capacitance of GOPM electrode retained about $97 \%$ of the highest capacitance even after continuous galvanostatic charge/discharge process for 5100 cycles, indicating a good cycling ability of the hybrid composites. The support carbon matrix GO allowed the strong deposition of PANI-protecting $\mathrm{MnO}_{2}$ nanorods on the surfaces of GO, which enhanced the mechanical strength of composite materials, resulting in the long charge/discharge ability. Interestingly, the specific capacitance showed slight increase in the first 150 cycles before decreased slowly in the later cycles, which may be explained with the insufficient contact of nanocomposites with $\mathrm{Na}_{2} \mathrm{SO}_{4}$ aqueous solution at the beginning of electrochemical measurement ${ }^{39,47}$.
The electrochemical properties of GOPM were further evaluated with electrochemical impedance spectroscopy (EIS). The impedance spectra of composite electrodes before and after 3000 cycles were measured in the frequency range of $100 \mathrm{kHz}-0.1 \mathrm{~Hz}$ at open circuit potential with an AC perturbation of $5 \mathrm{mV}$ (Fig. 8). Theoretically, an ideal Nyquist impedance plot features a semicircle over the high frequency region and a linear part in the low frequency range. The larger semicircle observed for the electrode corresponds to higher interfacial charge-transfer resistance $\left(\mathrm{R}_{\mathrm{ct}}\right)$ for the layer on the electrode, attributed to the poor electrical conductivity of the materials. And the straight line of the Nyquist plot corresponds to the resistance $\left(R_{s}\right)$ resulting from ion diffusion/transport, i.e., the more vertical line is indicative of an electrode more close to an ideal capacitor ${ }^{47}$. The equivalent series resistance (ESR) of pristine $\mathrm{MnO}_{2}$, GO-PANI, GOPM-46 and GOPM-70 obtained from the intersection of the Nyquist plot at the $\mathrm{x}$-axis is $2.6,0.7,1.8$, and $1.6 \Omega$, respectively. Considering the similar morphology of GO-PANI and GOPM, the difference in ESR of electrodes can be attributed to the different conductivities of electrode materials. The smaller ESR of GOPM than GO-PANI suggests the decreased charge transfer resistance in the presence of $\mathrm{MnO}_{2}$ nanorods as core ${ }^{48}$. The high resistance of ion transfer in GO-PANI would be attributed to high charge density, resulting in low capacitance. In contrast, GOPM-46 exhibited a short diffusion path length of ions in the electrolyte, which could be seen from the low resistance of the capacitative part on the Nyquist plot. This may be explained by the structure of the composite: the formation of GOPM results in the surface charge of GO being compensated by the negative charge from both $\mathrm{Cl}^{-}$doped PANI and $\mathrm{MnO}_{2}$ nanorods, leading to a lower resistance of ion transfer. Moreover, the presence of GO-PANI with high electrical conductivity resulted in a lower charge transfer ${ }^{37}$. After 3000 cycles, the calculated ESR for 

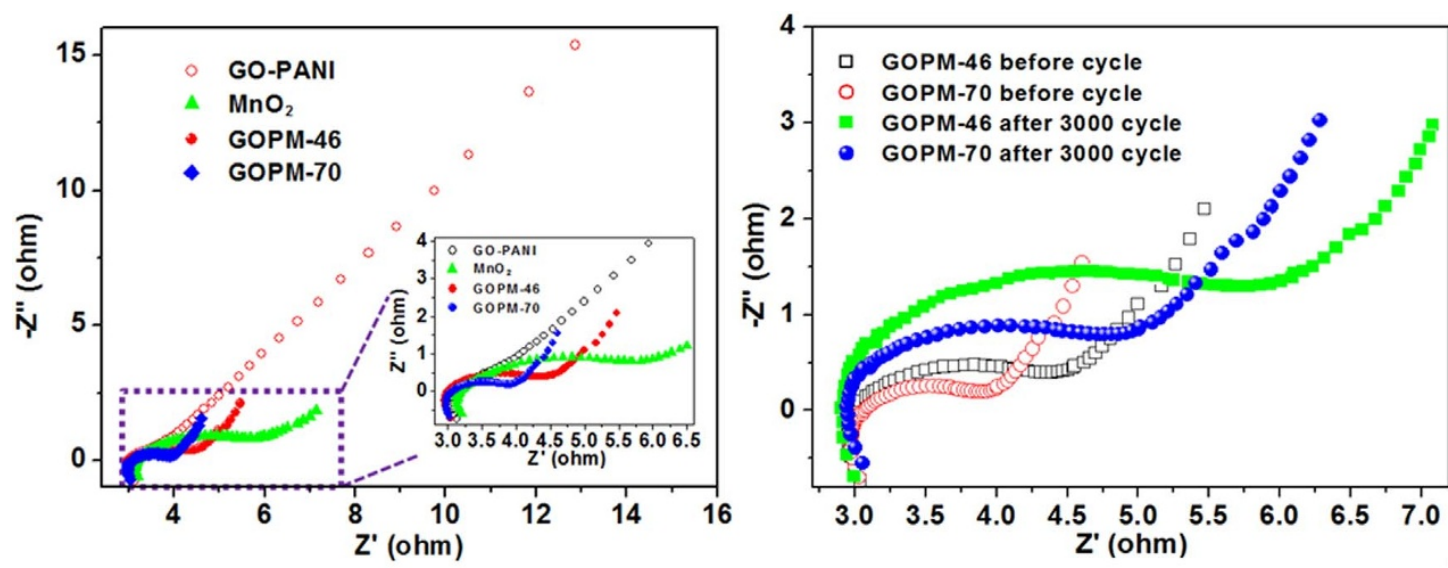

Figure $8 \mid$ Nyquist impedance plots of (a) $\mathrm{MnO}_{2}$, GO-PANI and GOPM composites before cycle and (b) GOPM after 3000 cycles.

GOPM- 46 based electrode increased from 1.8 to $2.4 \Omega$, while the ESR increased from 1.6 to $2.1 \Omega$ for GOPM-70. The increased resistance is probably attributed to the loss of adhesion of some active material with the current collector or the dissolution of some PANI/MnO 2 during the charge/discharge cycling.

\section{Discussion}

By using a quick and facile two-step process, $\mathrm{MnO}_{2}$ nanorods were successfully coated by in-situ prepared PANI and intercalated into GO sheets. The as-prepared ternary composites with different loading of $\mathrm{MnO}_{2}$ were evaluated as electrode materials for supercapacitors. The ternary composites presented highly porous nanostructure with significantly increased surface area $\left(91.37\right.$ and $73.65 \mathrm{~m}^{2} / \mathrm{g}$, respectively, for GOPM-70 and GOPM-46). With $\mathrm{MnO}_{2}$ nanorods to facilitate the charge transport in energy storage application, the ternary composites exhibited increased specific capacitance with the loading of $\mathrm{MnO}_{2}$ before a maximum reached at $70 \mathrm{wt} . \% \mathrm{MnO}_{2}$. The GOPM70 electrode exhibits a highest specific capacitance of $512 \mathrm{~F} / \mathrm{g}$ at $0.25 \mathrm{~A} / \mathrm{g}$ current density. With PANI conductive coating, the electrode showed high electrochemical stability in cycling, with $\sim 97 \%$ capacitance retention observed after 5100 cycles. Importantly, this design strategy may be employed for the fabrication of robust highperformance electrode with tailor-made hybrid composites composed of caboneous materials, conducting polymers and metal oxides.

\section{Methods}

Preparation of $\mathrm{MnO}_{2}$ nanorods ${ }^{\mathbf{4 0}}$. Absorbent cotton (200 mg) was added to $\mathrm{KMnO}_{4}$ solution $(40 \mathrm{mM}, 200 \mathrm{~mL})$ with simultaneous vigorous stirring and ultrasonic irritation for $20 \mathrm{~min}$. The mixture suspension was then heated at $100^{\circ} \mathrm{C}$ for $24 \mathrm{~h}$. A dark brown precipitate was obtained. The precipitates were collected by centrifugation and washed with deionized water and ethanol for 4 times. The title product was dispersed in hydrochloric acid $(1 \mathrm{M})$ for use.

Preparation of $\mathrm{MnO}_{2} / \mathrm{PANI} / \mathrm{GO}$ ternary hybrid nanostructures. Freshly prepared $\mathrm{GO}(0.1 \mathrm{~g})$ dispersion in water $(100 \mathrm{~mL})^{39}$ was ultrasonicated $(250 \mathrm{~W}, 220 \mathrm{~V})$ for $1 \mathrm{~h}$ to get an exfoliated yellow brown GO suspension. Aniline $(0.12 \mathrm{~g})$ was slowly added into the suspension and the stable $\mathrm{GO} /$ aniline suspension was obtained after stirring violently. A mixture of concentrated hydrochloric acid, ammonium persulfate (APS) in distilled water $(10 \mathrm{~mL})$ was then slowly added to the suspension under stirring. The molar ratio of aniline, hydrochloric acid and APS was $1: 1: 1$. When the reaction was conducted in ice bath for 10 minutes, $\mathrm{MnO}_{2}$ nanorods $(0.6 \mathrm{~g})$ dispersion in hydrochloric acid $(1 \mathrm{M}, 50 \mathrm{~mL})$ was added to the reaction system together with second addition of aniline $(0.12 \mathrm{~g})$. The reaction was stirred for $12 \mathrm{~h}$. Finally, the composite was filtered and rinsed with distilled water and ethanol in sequence to afford the title product $(0.65 \mathrm{~g})$ as a deep green solid.

Characterization. Thermogravimetric analysis (TGA) was conducted on a TA instrument TGA/SDTA 851 at $20^{\circ} \mathrm{C} / \mathrm{min}$ heating rate under nitrogen. Raman spectra were performed on a Renishaw laser confocal Raman spectrometer employing a $514 \mathrm{~nm}$ laser beam. The XRD patterns were recorded on an X-ray diffractometer (D8 Advance, Bruker, Germany) by using $\mathrm{Cu} K \alpha$ radiation $(\lambda=1.54 \AA)$ at $40 \mathrm{kV}$ and $30 \mathrm{~mA}$. XPS analyses were operated on a Thermo ESCALAB 250 instrument. Specific surface area of composites was measured on a BET (NOVA 1000, Quanta Chrome,
America) under nitrogen atmosphere at $77 \mathrm{~K}$. FE-SEM analyses were observed with a Hitachi S4800 FESEM at an accelerating voltage of $15 \mathrm{kV}$. TEM analyses were taken with a JEOL JEM-2100 microscope.

The electrochemical properties of the composite were investigated on a CHI660D electrochemical workstation (Shanghai, China) with conventional three-electrode system at room temperature. To prepare the working electrodes, the polytetrafluoroethylene with acetylene black (15 wt\%) in ethylene solution were added to as-prepared composites to produce a homogeneous paste before pressed onto nickel foam current collectors. The electrodes were then dried under vacuum at $60^{\circ} \mathrm{C}$ for $24 \mathrm{~h}$. The electrochemical performance of composites was investigated with standard CV, galvanostatic charge-discharge and EIS technique in $1 \mathrm{M} \mathrm{Na}_{2} \mathrm{SO}_{4}$ solution. CV measurements were performed in voltage ranging from $0 \mathrm{~V}$ to $0.8 \mathrm{~V}$ at a scan rate of $10,30,50$ and $100 \mathrm{mV} / \mathrm{s}$, respectively. Charge-discharge processes were carried out galvanostatically at $0.25 \sim 4 \mathrm{~A} / \mathrm{g}$ current density in $0 \sim 1 \mathrm{~V}$ voltage range.

1. Stoller, M. D., Park, S. J., Zhu, Y., An, J. \& Ruoff, R. S. Graphene-based ultracapacitors. Nano Lett. 8, 3498-3502 (2008).

2. Burke, A. Ultracapacitors: why, how, and where is the technology. J. Power Sources 91, 37-50 (2000).

3. Winter, M. \& Brodd, R. J. What are batteries, fuel cells, and supercapacitors? Chem. Rev. 104, 4245-4270 (2004).

4. Simon, P. \& Gogotsi, Y. Materials for electrochemical capacitors. Nat. Mater. 7, 845-854 (2008).

5. Liu, C., Li, F., Ma, L. \& Cheng, H. Advanced materials for energy storage. $A d v$. Mater. 22, E28-E62 (2010).

6. Fan, Z. et al. Asymmetric supercapacitors based on graphene/MnO2 and activated carbon nanofiber electrodes with high power and energy density. Adv. Funct. Mater. 21, 2366-2375 (2011).

7. Wei, T. et al. A cost-effective supercapacitor material of ultrahigh specific capacitances: spinel nickel cobaltite aerogels from an epoxide-driven sol-gel process. Adv. Mater. 22, 347-351 (2012).

8. Jiang, J. et al. Recent advances in metal oxide-based electrode architecture design for electrochemical energy storage, Adv. Mater. 24, 5166-5180 (2012).

9. Si, P., Ding, S., Lou, X.-W. \& Kim, D.-H. An electrochemically formed threedimensional structure of polypyrrole/graphene nanoplatelets for highperformance supercapacitors, RSC Adv. 1, 1271-1278 (2011).

10. Yuan, C. et al. Flexible hybrid paper made of monolayer $\mathrm{Co}_{3} \mathrm{O}_{4}$ microsphere arrays on rGO/CNTs and their application in electrochemical capacitors, $A d v$. Funct. Mater. 22, 2560-2566 (2012)

11. Chang, J., Lin, C. T. \& Tsai, W. T. Manganese oxide/carbon composite electrodes for electrochemical capacitors. Electrochem. Commun. 6, 666-671 (2004).

12. Zheng, J., Cygan, P. J. \& Jow, T. R. Hydrous ruthenium oxide as an electrode material for electrochemical capacitors. J. Electrochem. Soc. 142, 2699-2703 (1995).

13. Zhang, J.et al. Template synthesis of tubular ruthenium oxides for supercapacitor applications. J. Phys. Chem. C 114, 13608-13613 (2010).

14. $\mathrm{Wu}$, Z. et al. High-energy $\mathrm{MnO}_{2}$ nanowire/graphene and graphene asymmetric electrochemical capacitors. ACS Nano 4, 5835-5842 (2010).

15. Wang, D., Li, F. \& Cheng, H. Hierarchical porous nickel oxide and carbon as electrode materials for asymmetric supercapacitor. J. Power Sources 185, 1563-1568 (2008).

16. Pang, S., Anderson, M. A. \& Chapman, T. W. Novel electrode materials for thinfilm ultracapacitors: comparison of electrochemical properties of sol-gel-derived and electrodeposited manganese dioxide. J. Electrochem. Soc. 147, 444-450 (2000).

17. Cheng, F., Chen, J., Gou, X. \& Shen, P. High-power alkaline $\mathrm{Zn}-\mathrm{MnO}_{2}$ batteries using $\gamma-\mathrm{mno} 2$ nanowires/nanotubes and electrolytic zinc powder. Adv. Mater. 17, 2753-2756 (2005). 
18. Yan, J. et al. Fast and reversible surface redox reaction of graphene- $\mathrm{MnO}_{2}$ composites as supercapacitor electrodes. Carbon 48, 3825-3833 (2010).

19. Ma, R., Bando, Y., Zhang, L. \& Sasaki, T. Layered $\mathrm{MnO}_{2}$ nanobelts: hydrothermal synthesis and electrochemical measurements. Adv. Mater. 16, 918-922 (2004).

20. Bordjiba, T. \& Belanger, D. Direct redox deposition of manganese oxide on multiscaled carbon nanotube/microfiber carbon electrode for electrochemical capacitor. J. Electrochem. Soc. 156, A378-A384 (2009).

21. Bordjiba, T. \& Belanger, D. Development of new nanocomposite based on nanosized-manganese oxide and carbon nanotubes for high performance electrochemical capacitors. Electrochim. Acta 55, 3428-3433 (2010).

22. $\mathrm{Ma}$, S. et al. Electrochemical properties of manganese oxide coated onto carbon nanotubes for energy-storage applications. J. Power Sources 178, 483-489 (2008).

23. Dong, X. et al. $\mathrm{MnO}_{2}$-embedded-in-mesoporous-carbon-wall structure for use as electrochemical capacitors. J. Phys. Chem. B 110, 3019-6015 (2006).

24. Qian, Q., Lu, S. \& Gao, F. Preparation of $\mathrm{MnO}_{2}$ /graphene composite as electrode material for supercapacitors. J. Mater. Sci. 46, 3517-3522 (2011).

25. Yan, J. et al. Fast and reversible surface redox reaction of graphene- $\mathrm{MnO}_{2}$ composites as supercapacitor electrodes Carbon 48, 3825-3933 (2010).

26. Jiang, H., Ma, J. \& Li, C. Polyaniline- $\mathrm{MnO}_{2}$ coaxial nanofiber with hierarchical structure for high-performance supercapacitors. J. Mater. Chem. 22, 16939-16942 (2012)

27. Wang, J., Yang, Y., Huang, Z. \& Kang, F. Rational synthesis of $\mathrm{MnO}_{2} /$ conducting polypyrrole@carbon nanofiber triaxial nano-cables for high-performance supercapacitors J. Mater. Chem. 22, 16943-16949 (2012).

28. Yu, G. et al. Enhancing the supercapacitor performance of graphene $/ \mathrm{MnO}_{2}$ nanostructured electrodes by conductive wrapping. Nano Lett. 11, 4438-4442 (2011).

29. Yu, G. et al. Solution-processed graphene/ $\mathrm{MnO} 2$ nanostructured textiles for highperformance electrochemical capacitors. Nano Lett. 11, 2905-2911 (2011).

30. Wang, G., Tang, Q., Bao, H., Li, X. \& Wang, G. Synthesis of hierarchical sulfonated graphene $/ \mathrm{MnO}_{2} /$ polyaniline ternary composite and its improved electrochemical performance. J. Power Sources 241, 231-238 (2013).

31. Hou, Y., Cheng, Y., Hobson, T. \& Liu, J. Design and synthesis of hierarchical $\mathrm{MnO}_{2}$ nanospheres/carbon nanotubes/conducting polymer ternary composite for high performance electrochemical electrodes. Nano Lett. 10, 2727-2733 (2010)

32. Wang, H., Bian, L., Zhou, P., Tang, J. \& Tang, W. Core-sheath structured bacterial cellulose/polypyrrole nanocomposites with excellent conductivity as supercapacitors. J. Mater. Chem. A 1, 578-584 (2013).

33. Wang, H. et al. Bacterial cellulose nanofiber-supported polyaniline nanocomposites with flake-shaped morphology as supercapacitor electrodes. J. Phys. Chem. C 116, 13013-13019 (2012).

34. Novoselov, K. et al. Electric field effect in atomically thin carbon films. Science 306, 666-669 (2004).

35. Lee, C., Wei, X., Kysar, J. \& Hone, J. Measurement of the elastic properties and intrinsic strength of monolayer grapheme. Science 321, 385-388 (2008).

36. Park, S. \& Ruoff, R. Chemical methods for the production of graphenes. Nat. Nanotechnol. 4, 217-224 (2009).

37. Compton, O. \& Nguyen, S. Graphene oxide, highly reduced graphene oxide, and graphene: versatile building blocks for carbon-based materials. Small 6, 711-723 (2010).

38. Ma, S., Ahn, K., Lee, E., Oh, K. \& Kim, K. Synthesis and characterization of manganese dioxide spontaneously coated on carbon nanotubes. Carbon 45, 375-382 (2007).
39. Liu, Y. et al. Graphene/polypyrrole intercalating nanocomposites as supercapacitors electrode. Electrochim. Acta 112, 44-52 (2013).

40. Li, Q., Zhang, C., Xue, Z. \& Li, J. Preparation and characterization of polypyrrole microbelt via cotton template. J. Chin. J. Chem. Phys. 23, 207-210 (2010).

41. Fu, X., Feng, J., Wang, H. \& Ng, K. M. Room temperature synthesis of a novel $\gamma-$ $\mathrm{MnO}_{2}$ hollow structure for aerobic oxidation of benzyl alcohol. Nanotechnology 20, 375601 (2009).

42. Yang, H. \& Zeng, H. Preparation of hollow anatase $\mathrm{TiO}_{2}$ nanospheres via ostwald ripening. J. Phys. Chem. B 108, 3492-3495 (2004).

43. Gao, T. et al. Microstructures and Spectroscopic Properties of Cryptomelane-type Manganese Dioxide Nanofibers. J. Phys. Chem. C 112, 13134-13140 (2008).

44. Liu, Z., Ma, R., Ebina, Y., Takada, K. \& Sasaki, T. Synthesis and delamination of layered manganese oxide nanobelts. Chem. Mater. 19, 6504-6512 (2007).

45. Zhu, C., Guo, S., Fang, Y., Han, L. \& Wang, S. One-step electrochemical approach to the synthesis of graphene/ $\mathrm{MnO}_{2}$ nanowall hybrids. Nano Res. 4, 648-657 (2011).

46. Zhu, J. \& He, J. Facile synthesis of graphene-wrapped honeycomb $\mathrm{MnO}_{2}$ nanospheres and their application in supercapacitors. ACS Appl. Mater. Interfaces. 4, 1770-1776 (2012).

47. Nian, Y. R. \& Heng, H. Nitric acid modification of activated carbon electrodes for improvement of electrochemical capacitance. J. Electrochem. Soc. 149, A1008-A1014 (2002)

48. Han, G. et al. Sandwich-structured $\mathrm{MnO}_{2} /$ polypyrrole/reduced graphene oxide hybrid composites for high performance supercapacitors. RSC Adv. 4, 9898-9904 (2014).

\section{Acknowledgments}

This research project was financially supported by the National Natural Science Foundation of China (Grant No. 21074055), Program for New Century Excellent Talents in University (NCET-12-0633), Jiangsu Province Natural Science Fund for Distinguished Young scholars (BK20130032), Doctoral Fund of Ministry of Education of China (No. 20103219120008), and the Fundamental Research Funds for the Central Universities (30920130111006).

\section{Author contributions}

T.W. conceived the work. H.G., Z.L., L.Y. and Z.S. performed the experiments. H.G., K.E., T.J. and T.W. analyzed the data and prepared the manuscript.

\section{Additional information}

Competing financial interests: The authors declare no competing financial interests.

How to cite this article: Han, G.Q. et al. $\mathrm{MnO}_{2}$ Nanorods Intercalating Graphene Oxide/ Polyaniline Ternary Composites for Robust High-Performance Supercapacitors. Sci. Rep. 4, 4824; DOI:10.1038/srep04824 (2014).

This work is licensed under a Creative Commons Attribution-NonCommercialNoDerivs 3.0 Unported License. The images in this article are included in the article's Creative Commons license, unless indicated otherwise in the image credit; if the image is not included under the Creative Commons license, users will need to obtain permission from the license holder in order to reproduce the image. To view a copy of this license, visit http://creativecommons.org/licenses/by-nc-nd/3.0/ 